\title{
Clinico-hematological study of pancytopenia
}

\author{
Lakhey A ${ }^{1}$, Talwar $\mathrm{OP}^{2}$, Singh VK${ }^{2}$, KC Shiva Raj ${ }^{1}$ \\ ${ }^{1}$ Department of Pathology, KIST Medical College, Lalitpur, Nepal \\ ${ }^{2}$ Department of Pathology, Manipal Teaching Hospital, Pokhara Nepal
}

\section{Keywords: \\ Acute myeloid leukemia; Bone marrow; Megaloblastic anemia; Pancytopenia}

\begin{abstract}
Background: Pancytopenia refers to a reduction in all the three cellular elements of blood. The aim of this study was to identify the various causes of pancytopenia in patients attending to Manipal teaching hospital in Pokhara.

Materials and Methods: This was a cross-sectional study, carried out in Manipal teaching hospital from August 2008 to August 2010. Fifty-four patients with pancytopenia were included in the study. Complete blood count, bone marrow aspirations and trephine biopsies were performed. Data were analyzed using SPSS 11.0 version.

Results: Out of 54 cases, there were 16 cases (29.60\%) of hypoplastic bone marrow, 15 cases $(27.78 \%)$ of hematological malignancies, 13 cases $(24.10 \%)$ of megaloblastic anemia, 4 cases $(11.11 \%)$ of erythroid hyperplasia and 6 cases $(7.41 \%)$ of normcellular bone marrow. Acute myeloid leukemia was the commonest hematological malignancy.
\end{abstract}

Conclusion: The commonest cause of pancytopenia in our study was hypoplastic bone marrow followed by hematological malignancies and megaloblastic anemia.

\section{INTRODUCTION}

Pancytopenia is a reduction in all the three cellular elements of blood; exists in adult when the hemoglobin level is less than $10 \mathrm{~g} / \mathrm{dL}$, total leukocyte count is less than $4 \times 10^{9} / \mathrm{L}$, and platelet count is less than $150 \times 10^{9} / \mathrm{L}^{1}$ Pancytopenia can be due to decrease in hemopoietic cell production, ineffective haemopoiesis or peripheral destruction of the cells. The haemopoietic cell production can be influenced in the bone marrow by infections, toxins, malignant cell infiltration leading to hypocellular marrow. Ineffective hematopoiesis and dysplasia, maturation arrest of all the cell lines and peripheral sequestration of blood cells or peripheral destruction of all blood cells lineage can also be the cause of pancytopenia. ${ }^{2-5}$ Pancytopenia is a common hematological problem with an

\section{Correspondence:}

Dr. Ashish Lakhey, MD

Department of Pathology, KIST Medical College, Lalitpur, Nepal

Email: aashishlakhey@hotmail.com extensive differential diagnosis, and the optimal diagnostic approach to pancytopenia remains undefined..$^{6-8}$ Pancytopenia is not a disease but a triad of findings that may result from a number of disease processes. These disorders may affect bone marrow either primarily or secondarily, resulting in the manifestation of pancytopenia. ${ }^{9}$ The aim of this study was to identify the various causes of pancytopenia in patients attending to Manipal teaching hospital in Pokhara.

\section{MATERIALS AND METHODS}

Patients admitted to the hospital with pancytopenia through outpatient department or the emergency were enrolled in this study. Detail history and clinical examination were carried out. Various clinical and hematological parameters were noted including age at presentation and drug history. All the patients were subjected to examination of their complete blood count, peripheral blood smear, bone marrow aspiration and bone 
marrow biopsy. Peripheral blood smears were stained with Leishman stain. For reticulocyte count brilliant cresyl blue stain was used.

Bone marrow (BM) aspiration was performed from posterior superior iliac spine under aseptic condition. Slides were stained with routine Leishman stain and examined. Other special stains like Myeloperoxidase, Periodic acid and Schiff reagent were performed where necessary. Data were analyzed using SPSS 11.0 version.

\section{RESULTS}

Out of 54 cases 39 were males and 15 were females with male: female ratio of 2.6:1. The mean age was 40 years with a range of 5- 82 years. The findings of bone marrow study are given in Table 1. Hypoplastic bone marrow (fig.1) was the most common finding $(\mathrm{n}=16,29.6 \%)$. Among Hematological malignancies acute myeloid leukemia (AML) was the most common entity (fig.2). Hematological malignancies are summarized in Table 2.

The mean ages of ALL and AML were 14 and 37 years respectively. All cases of ALL occurred predominantly in children, the eldest being 17 years. Erythroid hyperplasia associated with pancytopenia was seen in younger patients $(\mathrm{m}=$ 26.17 years), where as the mean age of hypoplastic marrow, megaloblastic anemia and hematological malignancies were 48.25 years, 31.9 years and 47.38 respectively.

Anemia was the predominant presenting clinical feature (73.9\%). The $2^{\text {nd }}$ most common clinical feature was fever (26.1\%). Other presenting features were splenomegaly (13.1\%), lymphadenopathy (3.7\%), jaundice and bone tenderness $(1.9 \%$ each). Leukopenia and thrombocytopenia were frequently associated with leukemias compare to other non-malignant hematological conditions.

\section{DISCUSSION}

The mechanism by which pancytopenia develops appears to be either associated with decrease in haematopoietic cell production as a result of destruction of the marrow tissue by toxins, replacement by abnormal or malignant tissue, or perhaps suppression of normal growth and differentiation.
In some patients the marrow may be normocellular or even hypercellular. The present study comprised of 54 patients with pancytopenia, which included 39 males and 15 females with male:female ratio of 2.6:1. The mean age was 40 years with a range of 5-82 years. Adults: Children ratio was 6.7:1. Different male to female ratio and age range were observed in different studies. ${ }^{10-12}$

The most significant BM finding was hypoplastic bone marrow in about $29.6 \%$ of the cases of pancytopenia. Hematological malignancy $(29.6 \%)$ was the next frequently occurring cause, followed by megaloblastic anemia $(24.1 \%)$ and erythroid hyperplasia (11.11\%). The common causes of pancytopenia of this study are compared with the findings in other studies in Table 3.

In this study pallor was present in $73.9 \%$ of cases, followed by fever in $26.1 \%$, splenomegaly in $13.1 \%$ and $3.8 \%$ with bleeding abnormalities. Similar findings were observed in other studies. ${ }^{10,18}$ Mussarrat $\mathrm{N}$ et al ${ }^{9}$ showed $47.7 \%$ of cases with fever and $33.7 \%$ with bleeding. In the present study splenomegaly was seen in $13.1 \%$ of the cases with pancytopenia. The frequency of splenomegaly was comparable

Table 1: Bone marrow aspiration findings in case of pancytopenia

\begin{tabular}{llcc}
\hline Bone marrow findings & Male/Female & $\begin{array}{c}\text { No. of } \\
\text { cases }\end{array}$ & Percentage \\
\hline Hypoplastic bone marrow & $13 / 3$ & 16 & 29.6 \\
Hematological malignancies & $11 / 4$ & 15 & 27.78 \\
Megaloblastic anemia & $13 / 0$ & 13 & 24.1 \\
Erythroid hyperplasia & $1 / 5$ & 6 & 11.11 \\
\hline Normocellular bone marrow & $1 / 3$ & 4 & 7.41 \\
\hline Total & $\mathbf{3 9 / 1 5}$ & $\mathbf{5 4}$ & $\mathbf{1 0 0 \%}$ \\
\hline
\end{tabular}

Table 2: Hematological malignancies

\begin{tabular}{lcc}
\hline Hematological malignancies & No. of cases & Percentage \\
\hline Acute myeloid leukemia & 7 & $46.7 \%$ \\
\hline Myelodysplastic syndrome (MDS) & 4 & $26.6 \%$ \\
\hline Acute lymphoblastic leukemia (ALL) & 2 & $13.3 \%$ \\
\hline Non-Hodgkin lymphoma (NHL) & 1 & $6.7 \%$ \\
\hline Chronic lymphoid leukemia (CLL) & 1 & $6.7 \%$ \\
\hline Total & $\mathbf{1 5}$ & $\mathbf{1 0 0 \%}$ \\
\hline
\end{tabular}

Table3: Comparison of the findings of this study with other studies

\begin{tabular}{llll}
\hline Study & Cases & First cause & Second cause \\
\hline Keisu et al $^{13}$ & 100 & Neoplastic disease. Radiation (32\%) & Hypoplastic anemia(19\%) \\
Hossain et al $^{14}$ & 50 & Hypoplastic anemia & Chronic malaria and kalazar \\
Verma N et al $^{15}$ & 202 & Hypoplastic anemia(40.6\%) & Megaloblastic anemia(23.26\%) \\
Tilak N et al & & Megaloblastic anemia(68\%) & Hypoplastic anemia(7.7\%) \\
Kumar et al $^{17}$ & 77 & Hypoplastic anemia(29.51\%) & Megaloblastic anemia(22.3\%) \\
Khodke et al $^{10}$ & 166 & Megaloblastic anemia(44\%) & Hypoplastic anemia(14\%) \\
Present study & 50 & Hypoplastic anemia(29.6\%) & Hematological malignancies(27.78\%) \\
\hline
\end{tabular}




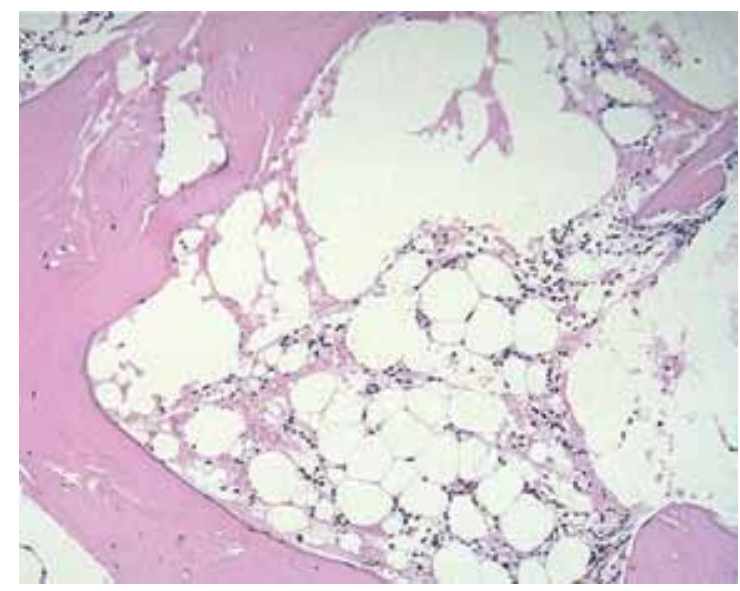

Figure 1: Trephine biopsy showing a predominantly fatty marrow between bony trabeculae with sparse marrow cellularity (HE stain, X200)

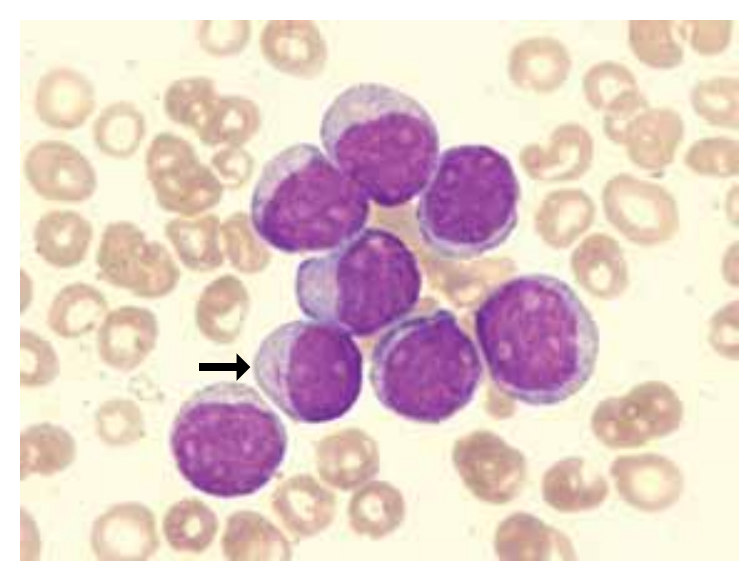

Figure 2: Bone marrow aspiration smears showing myeloblasts with multiple prominent nucleoli. Auer rod (arrow head) is seen in the cytoplasm (MGG stain, X1000)

to various studies. ${ }^{9,10}$

Pancytopenia can be seen in $30 \%$ of acute leukemia at the time of presentation..$^{10}$ In our study, $27.78 \%$ of patients presented with malignant etiology with pancytopenia and was the next most common cause of pancytopenia. AML was the most common malignancy diagnosed in $12.96 \%$ of the total cases whereas Jha A et al found AML to be $19.59 \%$ of total cases. ${ }^{10}$ AML (12.96\%) in the present study included more cases than erythroid hyperplasia $(11.11 \%)$ and normal bone marrow (7.41\%). Savage et $\mathrm{al}^{7}$ in Zimbabwe and Varma $\mathrm{N}$ et a ${ }^{15}$ also described AML as the third most common cause of pancytopenia.

In this study ALL comprised of $13.3 \%$ case; of the total hematological malignancy. The age range was from 1117 years with a mean of 14 years, showing involvement of children only. In other study, $28.21 \%$ of the hematological malignancies comprised of ALL with mean age of 13 years ranging from $2-33$ years. ${ }^{10}$
In the general populations MDS account for 5 per 1, 00,000 people. However, among individuals older than 70 years, the incidence increased from 22- 45 per 1,00,000 people and increasing further with the age. ${ }^{19}$ In this study, $7.4 \%$ of the total cases were diagnosed as MDS. The age group ranges from 3079 years.

In the present study, $24.1 \%(\mathrm{n}=13)$ cases with pancytopenia were diagnosed as megaloblastic anemia, and was the third most common cause of pancytopenia while in other similar studies it varied from $0.8 \%$ to $80 \%{ }^{9}$ Khanduri $\mathrm{U}$ et $\mathrm{a}^{20}$ found the incidence of megaloblastic anemia to be $64 \%$, and as the most common cause of pancytopenia. The high prevalence of nutritional anemia in India has been cited for increase in frequency of megaloblastic anemia. ${ }^{10}$ Chronically ill patients have been reported to have folic acid deficiency resulting in florid megaloblastic changes in the marrow precipitating into pancytopenia. ${ }^{17}$

In this study apart from pallor, splenomegaly (23\%), fever (7.7\%) and bony tenderness $(7.7 \%)$ were other clinical manifestation in the patients with megaloblastic anemia. Various studies have shown myriads of clinical features associated with megaloblastic anemia. Shazia $\mathrm{M}$ et al ${ }^{18}$ in their study have described the presenting features of megaloblastic anemia as pallor with varying degree of skin and mucosal bleedings. Bleeding manifestations was not seen in the present study. Osaman I et $\mathrm{al}^{8}$ have shown fever $(56.4 \%)$, bleeding (38.8\%), diarrhoea $(38.5 \%)$, anovexia $(35.9 \%)$ in patients with pancytopenia due to megaloblastic anemia. Khanduri et $\mathrm{al}^{20}$ mentioned predominant symptoms as fatigue, anorexia and gastritis, low grade fever, dyspnea and mild jaundice in megaloblastic anemia. Osaman I et $\mathrm{al}^{8}$ in their study found $15.4 \%$ of megaloblastic anemia with splenomegaly.

\section{CONCLUSION}

The commonest cause of pancytopenia in our study was hypoplastic bone marrow followed by hematological malignancies and megaloblastic anemia. There are varying trends in its clinical pattern, treatment modalities, and outcome depending on the different causes of pancytopenia which should be kept in mind while managing it.

\section{REFERENCES}

1. Frank F, Collin C, David P, Byran R, Editor. De Gruchey's clinical hematology in medical practice. 5th ed.Blackwell: Berlin; 2004. 119pp.

2. Kar M, Ghosh A. Pancytopenia. J Indian Acad Clin Med 2002;3:2934.

3. Lee GR, Bithell TC, Forester J, Athens JW, Lukens JN, editors. Wintrobe's Clinical Hematology. 10th ed. Philadelphia: Lee \& Febiger, 1999. pp1969-89.

4. Rodak RF. Hematology Clinical Principles and Applications. 2nd ed. Philadelphia: W.B. Saunders Company, 2002:63-94.

5. Pancytopenia. [Online]. 1998 March 20 [cited 1998 March 26]; Available from: URL: en.wikipedia.org/wiki/Pancytopenia. 
6. Rehman H, Mohammad F, Faiz M. Clinical presentation of pancytopenia in children under 15 years of age. J Postgrad Med Inst 2003; 17:46-51.

7. Savage DG, Allen RH, Gangaidzo IT et al. Pancytopenia in Zimbabwe. Am J Med Sci 1999;317:22-32.

8. Osama I, Haider ZB, Anwer F, Nisar H. Patterns of pancytopenia patients in a general medical ward and a proposed diagnostic approach. J Ayub Med Coll Abbottabsd 2004;16:8-13.

9. Niazi N, Raziq F.The incidence of underlying pathology in pancytopenia - An experience of 89 cases. J Postgrad Med Inst 2004;18:76-9.

10. Khodke K, Marwah S, Buxi G, Yadav RB, Chaturvedi NK. Bone marrow examination in cases of pancytopenia. J Indian Acad Clin Med 2001;2:55-9.

11. Jha A, Sayami G, Adhikari RC, Patna AD, Jha R. Bone marrow examination in cases of pancytopenia. J Nepal Med Assoc. 2008;47:12-7.

12. Qazi RA, Masood A. Diagnostic evaluation of pancytopenia. J Rawal Med Coll 2002;6:30-3.
13. Keisu M, Ost A. Diagnosis in patients with severe pancytopenia suspected of having aplastic anemia. Eyr J Haematol 1990; 45:11-4.

14. Hossain MA, Akond AK, Chowdhary MK et al. Pancytopenia-A study of 50 cases, Bangladesh Journal of Pathology 1992;1:9-12.

15. Varma N, Dash S. A reappraisal of underlying pathology in adult patients presenting with pancytopenia. Trop GeogrMed 1992;44:3227 .

16. Tilak V, Jain R. Pancytopenia - A clinico-hematologic Analysis of 77 cases. Indian J Pathol Microbiol 1999;42:399-404.

17. Kumar R, Kalra SP, Kumar H, Anand AC, Madan H. Pancytopenia A six year study. JAPI 2001;49:1078-81.

18. Shazia M, Salma S, Akhbar M, Nizsmani A. Etiological Spectrum of Pancytopenia based on Bone Marrow Examination. J Coll Physicians Surg Pak 2008;18:163-7.

19. Adil SN, Burney IA, Kakepoto GN, Kakepoto GN, Khurshid M. Epidemiological features of aplastic anemia in Pakistan. J pak Med Assoc 2001;51:443-5.

20. Khanduri U, Sharma A. Causative and prevelance of megaloblastic anemia. : Natl Med J India 2007;20:172-5. 